\title{
A study of aggression among adolescents of Jammu district in relation to Sex, self concept and socioeconomic status.
}

\author{
Mohan Galgotra, \\ Research Scholar Dept of Education, University of Jammu.
}

\begin{abstract}
The most difficult and challenging area in the sphere of aggression among individuals is that of aggression among adolescents. The research was designed as an initial attempt to assess aggression of adolescent and its relation to sexi, self concept and socioeconomic status. A sample of Adolescents ranged between 15-17 years was taken randomly from Jammu district of J\&K state. . All subjects completed Aggression inventory. Socio economic scale was used to assess the socioeconomic status of the subjects. Self concept scale was used to assess the self concept of adolescents. Three way ANOVA was employed to assess the correlation between aggression, self concept and socioeconomic status. Results provide evidence that aggression has a positive correlation with Sex, self concept and socioeconomic status. Boys show high aggressive behavior in comparison to their female counter parts. Further findings indicate that low socioeconomic students are significantly more aggressive than high socioeconomic status adolescents. Finally results show that low self concept adolescents are highly aggressive in comparison to high self concept adolescents.
\end{abstract}

Keywords : Aggression, self concept, socioeconomic status, gender.

\section{INTRODUCTION}

The human child comes into the world as a biological organism with animal needs. He is gradually molded in society into a social being and learns social ways of acting and feeling. He cannot survive with the help of others. From the very beginning of his life he becomes entangled in social relations, which are essential for his survival. The dependence of the child on the adult members prepares him to perform those behaviors which are approved by others. It is a well known fact that man has his physical as well as psychological needs. For fulfillment of these needs, he strives and behaves in a particular fashion which is known as purposeful or goal oriented behavior. In most of the cases the Person becomes successful but where there is a hurdle in the way he experiences failure and he feels tensions, conflict or frustration. His repeated failure to overcome this state produces different type of reactions in his/her behavior. If these reactions are maladaptive he/she becomes violent or aggressive.

\section{Rationale of the study}

The most difficult and challenging area in the sphere of aggression among individuals is that of aggression among adolescents. This is a stage in which it is very difficult to channelize the aggression for a better and more productive life of the concerned individual. Once the symptoms and manifestations of aggression are ignored at the adolescent, stage the aggressive adolescent may never be able to repair the self defeating strings of manifest aggression

$>$ In view of the seriousness of the aggression, great efforts have been made since many years to explore the cause behind it. In an investigation Huesmann et al., (1987) found that students with lower I.Q. , For example are likely to have poor self concept on academic ability and are likely to have poor self concept on academic ability and are also more likely to be aggressive. Sumbali (1980) conducted a PhD research work and found that the boys were more aggressive than girls both at senior level and junior level, Singh (1995) found differences in aggressive tendency between different levels of sex and different levels of classes when their joint influence was studied, Bertowitz (1993) found that Poor self concept may be experienced as or lead to an aversive emotional state/ aggression. Baumeister et al., (1996) found that when positive self views are challenged, individuals are more likely to become aggressive. Kour (2001) revealed that the adolescents did not differ significantly from each other, with frustration taken as criterion which ultimately lead to aggression but Pathania (2001)in her research found that boys were found to be more aggressive than girls and girls were found to be more resentful as compared to boys. Malcolm Watson et.al.(2004) studied pathways to aggression in children's and Adolescent and found that low cohesive families , high level of victimization by Peers and high behavioral inhibition have a significant role in the aggressive tendency among adolescents. Davis (2007) conducted a survey and found that older siblings who were aggressive tended to have younger siblings who were also aggressive to vice versa and Parent's hostility also plays a role in the development of aggression in their children.

Keeping in view the increase in study of aggression and its correlates, it is important to study the nature of aggression at adolescent stage as it is the most crucial stage of human development. The present study is also helpful in finding out, why individuals turn into aggressive, what are the manifestations of aggression in society and how can aggression be prevented and controlled. 
Objectives of the study

1 To find out the effect of main factor i.e., "Sex" on the aggression taken as criterion.

2 To find out the effect of 2 nd main factor i.e., "self concept" on the aggression taken as criterion.

3 To find out the effect of 3rd main factor i.e., "socioeconomic status" on the aggression taken as criterion.

4 To find out the double interactional effect of "sex and self concept" on the aggression taken as criterion.

5 To find out the double interactional effect of " sex and socio economic" on the aggression taken as criterion.

6 To find out the double interactional effect of "self concept and socio economic" on the aggression taken as criterion.

7 To find out the triple interactional effect of "sex, self concept and socioeconomic status" on the aggression taken as criterion

Hypothesis of the study

1 It is likely that "sex" has no significant effect on the aggression of adolescent, taken as criterion.

2 It is likely that "self concept" has no significant effect on the aggression of adolescent, taken as criterion.

3 It is likely that "Socioeconomic status" has no significant effect on the aggression of adolescent, taken as criterion.

4 It is likely that there is no significant interactional effect of "sex and self concept" on aggression taken as criterion.

5 It is likely that there is no significant interactional effect of "sex and socioeconomic status" on aggression taken as criterion.

6 It is likely that there is no significant interactional effect of "self concept and socioeconomic status " on aggression taken as criterion.

7 It is likely that there is no significant triple interactional effect of "sex, self concept and socioeconomic status on the aggression taken as criterion.

Delimitations of the study

Due to lack of time and other resources the study was carried out with the following limitations

- The study was restricted only on the adolescents ranged between 15-17 year of Jammu district.

- The study was limited to a sample of 250 boys and girls drawn from 20 schools of District Jammu.

- Only those schools were taken for the study which is affiliated to State Board of education.

- Only high socioeconomic status and low socioeconomic status adolescents were taken for the study.

- Only Govt. and private school students were taken for the study.

Sampling

The investigator selected randomly 10th class boys (125) and girls (125) Studying in different Government and Private schools for his research study. The sample was taken from Jammu City only.

Tools Employed

- $\quad$ Aggression scale prepared by Km. Roma Pal and Dr. (Smt) Tasneem Naqvi.

- Socio economic status scale by Verma and Sharma.

- Self concept inventory by Dr. Bina Shah.

Statistical Technique Employed

Three way (2x2x2) Analysis of variance was employed to find out the main and interactional effect of sex, Self concept and socioeconomic status on aggression among adolescents. 


\section{Procedure}

After administering of the tools on the sample, the scoring was done as per the description given the respective manuals of the standardized tools. Then the variables such as sex, socioeconomic status and self concept were dichotomized into boys and girls, high socioeconomic status and low socioeconomic status, self concept into high self concept and low self concept. A three way ANOVA with $(2 \times 2 \times 2)$ factorial design was employed to determine the influence of the 3 independent variables such as sex, self concept and socioeconomic status and their interactional effect on the dependent variable i.e., Aggression

\section{Results and Discussions}

Results and analysis relating to the influence of sex, socioeconomic status, type of institution and their interactions on Adolescent's Aggression are shown in Table 1.1

\begin{tabular}{|c|c|c|c|c|c|c|c|}
\hline \multicolumn{2}{|c|}{ Source of variation } & \multicolumn{2}{|c|}{$\begin{array}{l}\text { Degree of } \\
\text { Freedom }\end{array}$} & Sum of Squares & $\begin{array}{l}\text { Mean of sum of } \\
\text { squares }\end{array}$ & F-Value & $\begin{array}{l}\text { Significant/ } \\
\text { Insignificant }\end{array}$ \\
\hline \multicolumn{2}{|l|}{$\operatorname{Sex}(A)$} & \multicolumn{2}{|c|}{1852.81} & 1 & 1852.81 & 18.53 & Significant \\
\hline \multicolumn{2}{|c|}{ Self concept (B) } & \multicolumn{2}{|l|}{2940.31} & 1 & 2940.31 & 29.40 & Significant \\
\hline \multicolumn{2}{|c|}{$\begin{array}{l}\text { Socioeconomic } \\
\text { status }(\mathrm{C})\end{array}$} & \multicolumn{2}{|l|}{2173.61} & 1 & 2173.61 & 21.73 & Significant \\
\hline \multicolumn{2}{|c|}{$\mathrm{AB}$} & \multicolumn{2}{|l|}{94.62} & 1 & 94.62 & .95 & Insignificant \\
\hline \multicolumn{2}{|l|}{$\mathrm{BC}$} & \multicolumn{2}{|l|}{49.62} & 1 & 49.62 & .50 & Insignificant \\
\hline \multicolumn{2}{|l|}{$A C$} & \multicolumn{2}{|l|}{74.12} & 1 & 74.12 & .74 & Insignificant \\
\hline \multicolumn{2}{|l|}{$A B C$} & \multicolumn{2}{|l|}{6.60} & 1 & 6.60 & .67 & Insignificant \\
\hline \multicolumn{2}{|l|}{ WITHIN } & \multicolumn{2}{|l|}{7200.70} & 72 & 100.01 & & \\
\hline Groups & Boys & Girls & $\begin{array}{l}\text { High self } \\
\text { concept }\end{array}$ & $\begin{array}{l}\text { Low self } \\
\text { concept }\end{array}$ & $\begin{array}{l}\text { HIGH SOCIOE } \\
\text { STATUS }\end{array}$ & & $\begin{array}{l}\text { LOW } \\
\text { SOCIOECONOMIC } \\
\text { STATUS }\end{array}$ \\
\hline Mean & 77.4 & 67.75 & 66.53 & 78.65 & 67.38 & & 77.80 \\
\hline
\end{tabular}

The following conclusions can be drawn from Table 1 and Table 2

- There is a significant effect of sex on Aggression of the adolescents. Table 2 also clears the picture that boys are more aggressive in comparison to their female counter parts.

- There is a significant effect of self concept on Aggression of the adolescents. Table 2 also clears that low self concept students are more aggressive in comparison to private school students.

- There is a significant effect of socioeconomic status on Aggression of the adolescent. Table 2 also clears that low socioeconomic status students are more aggressive than High socioeconomic status students.

- There is no significant double interactional effect of sex and self concept on Aggression taken as criterion.

- There is no significant double interactional effect of sex and socioeconomic status on Aggression taken as criterion.

- There is no significant double interactional effect of self concept and socioeconomic status taken as criterion.

- There is no significant triple interaction of sex, self concept and socioeconomic status taken as criterion.

\section{Educational Implications}

The following educational implications emanates from the findings of the present study

One of the findings of the present study was that sex influences the aggression among adolescents. The quantum of aggression was found more among boys than the girls. It is known fact that aggression is useful when it is present in mild form otherwise it leads to serious ailments and mental complexes. Thus examples setup by parents and teachers may reduce aggression in boys. The parents can help the sons in sublimating their aggressive instincts into constructive works like painting, drawing, vocational courses and hobbies etc. In this manner aggression can be reduced to a minimum among boys and they will remain busy on their tasks. We could utilize youngster boys for fighting disease, fighting crimes, 
fighting filth and dirt and slovenliness. Many forms of competitive extra-curricular activities could be used for this purpose e.g., two gang leaders can be converted into rival candidates for an important post in the boys corporate bodies for various activities.

Disapproval and non corporeal form of penalization (like with drawl of privileges) should help children give up extreme form of tantrums. This will apply more to boys than girls. Younger boys should be offered other alternatives forms of achievement and rivalry with peers and crude forms of achievement and rivalry with peers and crude physical aggression controlled by conditioning.

As the boys were found to be more aggressive than girls, the aggressive are born with a desire to dominate others. This should be converted into an aspiration for responsible leadership by the school. The home too can put them in charge of some work they can control for others welfare and service. For boys a "Counseling Service" is must .What the administrations need to do is to institute a Diploma in counseling and another in social work and appoint one teacher holding such a qualification as a part time psychologist and part time social worker on teaching staff. His class work will be reduced accordingly.

The cultural poverty of home is related to aggression, as low socioeconomic status is also a powerful indicator of aggression. Low socioeconomic status of adolescents is certainly a cause for not fulfillment of certain requirements, which leads to frustration and aggression. Thus there is a great need to look this matter seriously. The policy makers needs to frame certain policies for upliftment of these low socioeconomic students by making free and compulsory high school education on the patterns of "Right to Free and Compulsory education 2009" . There is a great need to revise the criteria for providing pre matric scholarships not only to weaker castes, but also to poor and needy students whether they belong to open caste or weaker caste.

Poor self concept may be experienced as or lead to an aversive emotional state/ aggression (Bertowitz). Thus improving self concept and giving appropriate academic interventions may well reduce the likelihood of aggression for among adolescents.

\section{References}

- $\quad$ Best, J.W. and Kahn J.V. (1992):“Research in Education”: New Delhi Prentice Hall of India Pvt. Ltd.

- Buss, A.H. (1961): "The Psychology of Aggression”, New York: Wiley and Sons, Inc.

- D' Andrade, R.G. (1966): “The Development of Sex Difference”, Stanford Univ. Pr.

- Dollard, J., Dobb, L, Miller, N., Mower, O and Sears, R. (1939): Frustration and Aggression". New Haven: Yale University,

- Horney, K. (1950): "Neurosis and Human Growth", New York: W.Ws. Norton \& Co. Inc.

- Kagan, J. (1964): "Review of Child Development Research", Vol. I, New York: Russell Stage Foundation.

- Koul, Lokesh (1997): "Methodology of Education Research". Vikas Publishing House Pvt. Ltd. New Delhi.

- Lackeys, P. (1945): "Self-consistency: A Theory of Personality", Shrine String Press, Inc.

- Lewin, K. (1935): "A Dynamic Theory of Personality", New York: McGraw Hill Book Co.

- Mchinnay, Fred (1967): "Psychology of Personnel Adjustment", Printed in United States of America.

- $\quad$ Michel, W. (1966): "The Development of Sex Difference”, Stanford: Stanford University Press.

- Ray Dutta S. (1979): "Psychology Disorders of Young Children" Sterling Publishers Pvt. Ltd.

- Sumbali, Kiran (1980): "A Study of Aggression among Children and Adolescents" Ph.D. Thesis, submitted to the Department of Education, University of Jammu, Jammu

- Singh, Ranjit (1995): "A Study of Aggression among Adolescents in Rural Areas" Unpublished M.A. Education dissertation submitted to Department of Education, University of Jammu.

- Bharti, Dheeraj (2003): “A Study of aggression among adolescents" Unpublished M.A. Education dissertation submitted to Department of Education, University of Jammu.

- Mahajan, Palavi (2008): "A Study of aggression among children in relation to sex and school: unpublished M.A. Education dissertation submitted to Department of Education, University of Jammu. 